\section{Complementary and alternative medicine use in families of children with cerebral palsy}

\author{
Edward A Hurvitz* MD; \\ Christina Leonard; \\ Rita Ayyangar MD; \\ Virginia Simson Nelson MD MPH, Department of Physical \\ Medicine and Rehabilitation, Pediatric Section, University of \\ Michigan Medical Center/Charles Stewart Mott Children's \\ Hospital, Ann Arbor, MI, USA.
}

*Correspondence to first autbor at Department of PM\&R, CS Mott Hospital F7822, Ann Arbor, MI 48109-0230, USA. E-mail: ehurvitz@umich.edu

In order to assess patterns of usage of complementary and alternative medicine (CAIM) in families of children with cerebral palsy (CP), 213 families with a child ( 0 to 18 years) with $\mathrm{CP}$ were recruited at the university medical center in Ann Arbor, MI, USA as part of a descriptive survey. Two hundred and thirty-five surveys were distributed. Mean age of the child was 8 years 6 months (SD 4y:9mo) and $56 \%$ of the sample was male with $35 \%$ full-time independent ambulators, while the rest used an assistive device or a wheelchair. Fifty-four percent were in special education classrooms. Families were given a survey on functional status of the child with CP, CAMI usage of the child and the parent, factors influencing the decision to use CAII, demographics, and clinical information. Of the families, $\mathbf{5 6 \%}$, used one or more CAIM techniques. Massage therapy (25\%) and aquatherapy (25\%) were the most common. Children of families that used CAMI were significantly younger ("y:9mo, SD 4y:"\%mo) than non-users (9y:6mo, SD 4y:6mo: $t$-test $p<0.01$ two-tailed). Children with quadriplegic CP, with spasticity, and those who could not walk independently were more commonly exposed to CAMI (Pearson's $\chi^{2}\left[\mathbf{P} \chi^{2}\right] p=0.01$ two-tailed; for mobility, odds ratio [OR] of 2.5 with regression). Mothers with a college degree had a greater tendency to use CAM for their child than those without $\left(\mathbf{P} \chi^{2} p=0.01\right.$ twotailed). Fathers of children who used CAMI were older than fathers of those who did not (3\%y:9mo versus $33 \mathrm{y}: 2 \mathrm{mo}, p=0.04$ two-tailed). There was no significant difference between groups for mother's age, father's education, income, or for population of home town. Parents who used CAM for themselves were more likely to try CAIM for their child ( $20 \%$ versus $4 \% \%$, OR 2.1), and were much more likely to be pleased with the outcome (' $1 \%$ versus $42 \%$, OR 3.5). Child's age (younger), lack of independent mobility, and parental use of CAM were the most significant predictive factors identified via logistic regression.
Complementary and alternative medicine (CAM) is becoming increasingly widespread in the USA. The study by Eisenberg and colleagues (1998) found that 83 million Americans had used at least one alternative therapy, an increase of $25 \%$ from his earlier studies. Estimated out-of-pocket expenditures were up to 34 billion dollars (Eisenberg et al. 1993,1998). Astin found a prevalence of $40 \%$ use of CAM among adults, generally associated with chronic health problems (1998). CAM use is fairly common in children as well, particularly in children with disabilities. Up to $50 \%$ of children with autism use some form of CAM (Nickel 1996). About one half of pediatricians surveyed in 1998 said that they would consider recommending alternative therapies to their patients (Sikand and Laken1998).

Spigelblatt and coworkers (1994) performed a survey of families' use of CAM for their children. They noted that $11 \%$ of the children seen in their general pediatric clinic had seen CAM practitioners in the past. Their study did not include overthe-counter products or individual practices. Chiropractic care was the most common form of CAM employed. Ottolini et al. (2001) found that $21 \%$ of children in the Washington DC area had used CAM, but only about one-third of those had actually gone to a CAM practitioner. The rest had used home remedies such as vitamins and herbal preparations.

The definition of CAM used in this study is that offered by the National Center for Complementary and Alternative Medicine (NCCAM) : '... a group of diverse medical and health care systems, practices, and products that are not presently considered to be part of conventional medicine.' (NCCAM, 2002; www.nccam.nih.gov).

The NCCAM defines five major domains of CAM: (1) alternative medical systems, such as Chinese medicine and homeopathy; (2) mind-body interventions such as meditation, hypnosis, and prayer; (3) biological-based therapies such as herbal medicines, shark cartilage for arthritis and cancer, and megavitamins as used to treat a variety of conditions; (4) manipulative and body-based therapies such as chiropractic manipulation and massage; (5) energy therapies such as magnetic therapy, therapeutic touch, and light therapies.

Despite the definitions and categorization, it is still challenging to determine what modalities and treatment methods should be included in a survey on the use of CAM. For example, acupuncture seems to be a certain candidate for the CAM list, but it is taught in many medical schools and commonly practised by physicians who are not identified as alternative or Chinese medicine practitioners. There is even a group of physicians (the American Academy of Medical Acupuncture) which promotes the use and study of acupuncture (www.medicalacupuncture.org). On the other hand, counseling and selfhelp groups are listed under mind-body interactions, but many studies of alternative medicine do not include interventions such as these on their lists. Prayer also presents a unique problem in terms of assessing use of alternative medicine - about $80 \%$ of Americans attend religious services, or a least feel that religion is an important part of their lives (Sheler 2002). It is doubtful that including all of these individuals in a study of CAM use would provide useful information about patterns of use.

Astin (1998) identified several factors that predicted use of alternative therapies in adults. These include higher education, a history of chronic health problems, and a holistic health philosophy. Race, ethnicity, sex, income, and age did not influence choice. Individuals with negative attitudes about CAM had used a CAM technique about as often as those who reported 
positive or other attitudes. Children generally do not choose CAM or any other form of medical care. Therefore, studies looking at children's use of CAM need to focus on what factors cause their parents to choose CAM for them. Spigelblatt et al. (1994) found that higher maternal education and CAM use among parents were predictive of CAM use for children. Children using CAM tended to be older (greater than 1 year old) than those who did not use CAM. Ottolini and colleagues' (2001) results concurred that children using CAM were older, and that the parents tended to be CAM users. They also noted that the parents were somewhat older.

All studies, both of adults and children, have noted a trend toward the use of CAM in chronic diseases or conditions. There are several studies of CAM use for specific pediatric syndromes such as pain (Rusy and Weisman 2000), attention-deficit-hyperactivity disorder (Baumgaertel 1999), asthma (Kemper 1996), cancer (Friedman et al. 1997), cystic fibrosis (Stern et al. 1992), and juvenile rheumatoid arthritis (Southwood et al. 1990). A

Table I: Demographic and clinical data

\begin{tabular}{|c|c|c|c|}
\hline & All participants, $\%$ & CAM users, \% & Non-CAM users, \% \\
\hline Sex (male) & 56 & 61 & 49 \\
\hline Mean (SD) age, $y: m^{a}$ & 8:6 (SD 4:9) & 7:9 (SD 4:7) & $9: 6(\mathrm{SD} 4: 6)$ \\
\hline \multicolumn{4}{|l|}{ Type of CPb } \\
\hline Quadriplegia & 41 & 49 & 37 \\
\hline Diplegia & 31 & 28 & 31 \\
\hline Hemiplegia & 22 & 17 & 31 \\
\hline Other & 6 & 6 & 1 \\
\hline \multicolumn{4}{|l|}{ School setting } \\
\hline Regular classroom (some with resource room) & 37 & 37 & 37 \\
\hline Special education class & 54 & 54 & 54 \\
\hline Other & 9 & 9 & 9 \\
\hline \multicolumn{4}{|l|}{ Symptoms (caregiver report) } \\
\hline Spasticity ${ }^{\mathrm{a}}$ & 72 & 80 & 63 \\
\hline Cognitive impairment & 36 & 33 & 39 \\
\hline Vision problems & 34 & 38 & 30 \\
\hline Seizures & 30 & 28 & 34 \\
\hline Pain & 21 & 24 & 18 \\
\hline Scoliosis & 19 & 20 & 17 \\
\hline Contractures & 13 & 13 & 14 \\
\hline Attention deficit & 9 & 7 & 10 \\
\hline \multicolumn{4}{|l|}{ Treatment history } \\
\hline Physical therapy & 99 & 99 & 99 \\
\hline Occupational therapy & 93 & 92 & 96 \\
\hline Botox/Phenol injections & 60 & 64 & 56 \\
\hline Casting & 34 & 36 & 32 \\
\hline Orthopedic surgery & 29 & 29 & 28 \\
\hline Oral spasticity medications & 21 & 25 & 17 \\
\hline Dorsal rhizotomy & 14 & 15 & 13 \\
\hline Electric stimulation & 12 & 15 & 8 \\
\hline Baclofen pump & 3 & 2 & 4 \\
\hline \multicolumn{4}{|l|}{ Mobility ${ }^{b}$} \\
\hline Independent ambulation & 35 & 27 & 45 \\
\hline Ambulates with assistance & 12 & 18 & 5 \\
\hline Some wheelchair use & 16 & 22 & 10 \\
\hline Full time wheelchair user & 37 & 33 & 40 \\
\hline \multicolumn{4}{|l|}{ Brace use } \\
\hline Lower extremity & 77 & 76 & 79 \\
\hline Upper extremity & 16 & 20 & 10 \\
\hline Trunk & 7 & 8 & 7 \\
\hline \multicolumn{4}{|l|}{ Feeding } \\
\hline Self feeding & 75 & 74 & 76 \\
\hline Gastrostomy tube & 11 & 11 & 11 \\
\hline \multicolumn{4}{|l|}{ Communication } \\
\hline Verbal & 71 & 70 & 71 \\
\hline Facial expression & 23 & 26 & 20 \\
\hline Other & 6 & 4 & 9 \\
\hline \multicolumn{4}{|l|}{ Fine motor } \\
\hline Colors or scribbles & 63 & 64 & 62 \\
\hline Pincer grasp & 54 & 54 & 54 \\
\hline
\end{tabular}

${ }^{\mathrm{a}} p<0.01$ two-tailed; ${ }^{\mathrm{b}} p=0.01$ two-tailed. NB: all results given in $\%$ except for age. 
review of the literature, however, did not reveal a survey focused on the families of children with cerebral palsy (CP). There has been a marked increase in interest in new treatment modalities for CP. Many of these methods are alternative approaches to treating motor dysfunction associated with CP. They include hippotherapy (involving horses as a therapeutic tool) and aquatherapy (gross motor therapy performed in a pool). Some of these new ideas have come from overseas, such as the Euromed Adeli Suit program from Poland (www.euromed.pl) and the conductive education approach from the Peto Institute in Hungary (www.petoinstitute.org). Other methods of CAM, such as massage therapy (Ireland and Olson 2000) and chiropractic manipulation (Balon et al. 1998) are popular with children, but their use in CP has not been documented.

Sikand and Laken (1998) found that only about one-half of pediatricians discussed CAM with their patients and that, generally, the conversation was started by the patient. Ottolini et al. (2001) noted that most pediatricians feel that their lack of knowledge interferes with their ability to discuss CAM with their patients. They emphasize a need for greater education about CAM, a thought echoed by Eisenberg et al. (1993). The aim of this study was to determine the prevalence of CAM use in a population of families of children with $\mathrm{CP}$, and to determine what factors influence the choice of CAM along with or as instead of 'standard care'. Our goal is to increase knowledge about CAM in children with CP in order to help practitioners in advising their patients about its use.

Table II: Family information

\begin{tabular}{lr}
\hline Measured items & $\%^{\mathrm{a}}$ \\
\hline One or more siblings in family & 72 \\
Mean (SD) age of parents/caregivers, y:m & \\
Female & $37: 2$ (SD10:2) \\
Male & $35: 9$ (SD 15:2) \\
Parent/caregiver education & 4 \\
Female & 49 \\
Did not complete high school & 47 \\
High school graduate & \\
College graduate & 9 \\
Male & 49 \\
Did not complete high school & 42 \\
High school graduate & \\
College graduate & 68 \\
Income (US $\$$ per year) & 21 \\
Female & 9 \\
$<25000$ & 1 \\
$25000-49999$ & 1 \\
$50000-99999$ & 14 \\
100000 or more & 34 \\
No female caregiver & 36 \\
Male & 9 \\
$<25000$ & 79 \\
$25000-49999$ & 24 \\
$50000-99999$ & 30 \\
100000 or more & 19 \\
No male caregiver & \\
Population of home town & \\
$<10000$ & \\
$10000-49999$ & \\
$50000-99999$ & \\
100000 or more & \\
&
\end{tabular}

${ }^{\mathrm{a} A l l}$ results given in \% except age.

\section{Method}

PARTICIPANTS

Participants were families of children with CP. Families consisted of, at the very least, the child and their primary caregiver. Children were aged 0 to 18 years inclusive and had a well-established diagnosis of CP on their medical records. Participants were recruited consecutively at their appointments at a pediatric rehabilitation clinic at a tertiary medical center in Ann Arbor, MI, USA. If the primary caregiver was not present (e.g. child brought in by grandmother who is not a regular caregiver), did not speak English, or was not willing to complete the survey, the family was excluded from the study.

\section{PROCEDURE}

A survey was developed that asked questions in three main areas. First, the survey queried the child's clinical history, including type of $\mathrm{CP}$, symptoms, complications, educational setting, and treatment history. For type of $\mathrm{CP}$, diplegic CP was defined as 'legs much more involved than arms', while quadriplegia was defined as 'arms and legs both significantly involved'. For educational setting, the family was asked about school designation (according to level of impairment) but due to different designations in different areas, this was reduced to special education classroom versus regular classroom versus a mixed setting.

The second area was function, including mobility, method of communication, orthotic use, feeding, and selected fine motor skills. Mobility was divided into 'walks without assistive devices', 'walks with assistive devices', 'uses a wheelchair some of the time', and 'always uses a wheelchair'. If the primary caregiver checked two categories, such as 'walks with assistive devices' and 'uses a wheelchair some of the time', the latter was recorded as the response.

Third, demographics, including age, sex, parents' ages, level of education, income, and the population of the family's home town were noted. Information on mother and father were recorded separately. Information on income of the family unit is not available, as marital status was not recorded and information regarding both incomes was not determined.

The survey then asked several questions about the use of CAM, including a list of CAM methods that are fairly common or were known (by the authors) to be used in children with CP. The list was drawn from the NCCAM listing of CAM methods. Alternative mobility therapies, such as conductive education and the Polish Adeli Suit program, were added to the list due to the prevalent use of them in children with CP. Interventions such as counseling and belonging to a support group were excluded, as it was felt that most participants would not view them as alternative and become confused by their inclusion. A space was included to write in therapy modalities not on the main list. Survey questions requested information about the frequency of therapies, the cost of therapies, and whether the therapies were administered or supervised by a professional. Families were asked their reasons for choosing these therapies, and if they were happy with the outcome of the treatment. The primary caregiver was then asked to record their own experiences with CAM, and if they were pleased with any treatment they might have received.

The survey was reviewed by pediatric rehabilitation professionals (aside from the authors) and by primary caregivers of children with $\mathrm{CP}$ for readability and ease of use. As a test of validity, families were asked to fill out the survey, and then 
their answers were reviewed to make sure that their answers matched their actual experiences. The survey and the study methods were approved by the Institutional Review Board at the University of Michigan Medical School.

\section{Intervention}

The survey was offered to consecutive families in the pediatric rehabilitation clinics who matched criteria. It was generally filled out while awaiting the physician's arrival. A few surveys were taken home, with about half of these mailed back to the investigators. Two hundred and thirty-five surveys were distributed. Seven surveys were discarded due to inadequate data (no basic demographic data, no information in the section about CAM use). Fifteen were not returned by mail or refused after initial acceptance. A total of 213 families completed the survey.

\section{ANALYSIS}

The main outcome variable in the analysis was CAM use versus no CAM use. Possible predictive factors assessed included age and sex of participant, type of CP, mobility status, educational setting, communication, parental age, income, education, and history of CAM use. A secondary analysis was done of families whose child used CAM, comparing those satisfied with outcome of treatment versus not satisfied, using the same factors. Standard statistical methods, including $t$-test, Pearson's $\chi^{2}$, and regression analysis were used. Data were recorded in Microsoft Access, and analyzed using SPSS (version 10.1).

\section{Results}

DEMOGRAPHICS AND CLINICAL DATA

Background demographics and clinical data are recorded in Table I. Information about the family is noted in Table II.

USE OF CAM

Data on the use of CAM is recorded in Table III. CAM was used by $56 \%$ of the families for their child. Children of families that used CAM were significantly younger $(7 \mathrm{y}: 9 \mathrm{mo}, \mathrm{SD} 4 \mathrm{y}: 7 \mathrm{mo})$ than non-users (9y:6mo, SD 4y:6mo; $t$-test $p<0.01$ two-tailed. Data also suggested that families of children who had greater motor disabilities tended to use CAM more often. For example, children with quadriplegic CP were more commonly exposed to CAM (Pearson's $\chi^{2}\left[\mathrm{P} \chi^{2}\right] p=0.01$ two-tailed) as were children whose parents identified spasticity as symptom of their $\mathrm{CP}\left(\mathrm{P} \chi^{2}\right.$ $p<0.01$ two-tailed). Children who could not walk independently were also more likely to have been treated with a CAM modality ( $\mathrm{P} \chi^{2} p<0.01$ two-tailed). Ability to speak, method of nutrition (oral versus gastostrostomy tube), and presence of fine motor skills (pincer grasp, scribbling, manipulating small objects or utensils) was not predictive of CAM use.

PATTERNS OF CAM USE

The most common forms of CAM were massage therapy (25\%), aquatherapy (25\%), and hippotherapy (17\%). The outcome of the CAM therapy was considered positive by $56 \%$ of the families who used it. About $60 \%$ of the families who used CAM used multiple methods. Spasticity or muscle tightness was the most common symptom for which the families sought CAM therapy (noted by $55 \%$ of the $57 \%$ of CAM users who answered this question), followed by help with balance (13\%). Other symptoms included increasing strength, decreasing pain, increasing mobility, and behavioral issues. Families who used
CAM dedicated a great deal of time to these therapies, with $75 \%$ of them using CAM at least weekly, and about half continuing their regular physiotherapy and occupational therapy during or around the time they were using CAM. Answers from questions on payment for CAM were hard to interpret, but about $42 \%$ of the families paid some money out of their own pocket for CAM, and $23 \%$ were able to obtain some insurance coverage.

REASONS FOR USING CAM

Families were referred to CAM by a number of sources, including their friends and family (25\%), therapists (16\%), and/or physician (14\%). As a sign of the times, $7 \%$ listed the internet as the main source of information that led to their use of CAM. When asked the reason for choosing a CAM method for treatment, almost half of the families noted that they felt it could improve the quality of their child's life. About $40 \%$ felt it could act to assist the more traditional methods of treatment their child was receiving. Less than $1 \%$ stated that they did not trust traditional medicine (Table IV). Children receiving treatment were asked their opinion in $23 \%$ of families. The family doctor was often asked (48\%) or at least informed (56\%) about the use of CAM. The doctor noted a change in about one-third of the children after CAM therapies, according to the primary caregiver. There was no correlation between doctors noting a change and a particular form of CAM.

PARENTAL FACTORS IN CHOICE OF CAM

A history of parental use of CAM appeared to be a major factor in the family choosing CAM for the child with CP. As noted in Table V, the primary caregiver had used CAM in 38\% of the families. A striking $69 \%$ of these families chose CAM for their

\section{Table III: CAIM use}

\begin{tabular}{ll}
\hline Families using CAM & $56 \%$ \\
Families using CAM pleased with results & $56 \%$
\end{tabular}

\begin{tabular}{|c|c|}
\hline Types of CAM used & $\%$ of total CAM users \\
\hline Massage therapy & 25 \\
\hline Aquatherapy & 25 \\
\hline Hippotherapy & 18 \\
\hline Chiropractic manipulation & 12 \\
\hline Conductive education & 10 \\
\hline Craniosacral therapy & 8 \\
\hline Euromed/Adeli Suit programa & 6 \\
\hline Hyperbaric oxygen & 6 \\
\hline Special dietary therapy & 6 \\
\hline Homeopathy & 4 \\
\hline Acupuncture/acupressure & 3 \\
\hline Feldenkrais method ${ }^{\mathrm{a}}$ & 2 \\
\hline Interactive light therapy & 2 \\
\hline Reflexology & 2 \\
\hline $\begin{array}{l}\text { Other (Includes Reiki }{ }^{\mathrm{a}}, \text { cranial electric s } \\
\text { magnets, Ayurveda }{ }^{\mathrm{a}} \text { ) }\end{array}$ & ion, \\
\hline Prayer as a 'treatment method' & 40 \\
\hline Frequency of treatment ( $61 \%$ of CAM us & onded) \\
\hline More than once a week & 42 \\
\hline Weekly & 33 \\
\hline Monthly or less & 14 \\
\hline Very infrequent (Tried once or twice) & 11 \\
\hline
\end{tabular}

${ }^{a}$ See Appendix I for CAM definitions. 
child, while only $47 \%$ of the caregivers who had never tried CAM themselves selected a CAM method for the child. (P $\chi^{2}$ $p<0.005$ two-tailed.) In addition, these families were much more likely to be pleased with the outcome of CAM for their child ( $71 \%$ versus $43 \%, \mathrm{P} \chi^{2} p<0.005$ two-tailed). Mothers with a college degree were more likely to use a CAM intervention for their child ( $\mathrm{P} \chi^{2} p=0.02$ two-tailed). Fathers whose children used CAM were slightly older (37y:9mo, SD 12y:10mo) than the others (33y:2mo, SD 17y:5mo, $p=0.042$ tailed). There was no significant difference between groups for mother's age, father's education, income or for population of home town. Family size (i.e. presence of siblings) also was not predictive of CAM use.

Table IV: Reasons for choosing CAIM

It would improve quality of life

It would relieve some symptoms

Fewer side effects

More control over my child's care

It won't do any harm

It would relieve all symptoms

I don't trust traditional medicine

Table V: Parental CAMI use

\begin{tabular}{|c|c|}
\hline $\begin{array}{l}\text { Parents who used CAM } \\
\text { Pleased with their own CAM use }\end{array}$ & $\begin{array}{l}38 \% \\
88 \%\end{array}$ \\
\hline Type CAM used & $\%$ of total CAM users \\
\hline Chiropractic manipulation & 58 \\
\hline Massage therapy & 51 \\
\hline Homeopathy & 15 \\
\hline Aquatherapy & 10 \\
\hline Reflexology & 5 \\
\hline Craniosacral therapy & 5 \\
\hline Acupuncture/acupressure & 4 \\
\hline Hypnosis & 4 \\
\hline Special dietary therapy & 4 \\
\hline Hippotherapy & 4 \\
\hline Feldenkrais method $^{\mathrm{a}}$ & 2 \\
\hline Interactive light therapy & 2 \\
\hline Other (Yoga, rolfing ${ }^{\mathrm{a}}$, visual therapy) & 8 \\
\hline
\end{tabular}

asee Appendix I for CAM definitions.
REGRESSION ANALYSIS

A stepwise logistic regression was performed to determine interaction between variables. Parental use of CAM, younger age of the child, and lack of independent ambulation were the most significant predictors of CAM use (Table VI). $\mathrm{R}^{2}$ value of the model was about 0.10 , indicating that the model only predicts $10 \%$ of the variability associated with choice of CAM for the child. Each of the three factors was about even in predicting variability. Parental use of CAM was the only factor that was predictive of parental satisfaction with the child's CAM therapies. (odds ratio 3.3, 95\% confidence interval 1.5 to 7.0$)$.

\section{Discussion}

Complementary and alternative medical treatments are of great interest to families of children with $\mathrm{CP}$, with a usage prevalence of $56 \%$ noted on this survey. This percentage is significantly higher than that noted in studies of CAM usage in the general pediatric clinic population, noted to be 11 to $21 \%$ (Spigelblatt et al. 1994, Ottolini et al. 2001), but consistent with CAM usage noted in other populations of children with chronic disease such as cancer (Friedman et al. 1997) and juvenile rheumatoid arthritis (Southwood et al. 1990), where prevalence as high as $70 \%$ has been noted. There are several possible reasons to consider for this difference. First, it must be noted that a university clinic may tend to draw a higher percentage of children at the severe end of the spectrum of CP. In this group, for example, $41 \%$ of the participants were diagnosed with quadriplegia. As noted in this study, children with more severe disability tended to be involved in CAM more often; this, therefore, may have led to a higher overall percentage. Second, definitions of CAM and choices of which therapies to include or exclude will certainly strongly affect the reported percentage of use. Spigelblatt et al. (1994), for example, probably significantly underestimated the use of CAM in their population by limiting their positive responses to children who had actually seen a CAM practitioner. On the other hand, we suspect that many readers may take exception to some of our choices for inclusion in this survey, such as aquatherapy and hippotherapy. Some practitioners may feel that these or other therapies that are on our list have entered the realm of standard care, especially for children with CP. Alternative medicine, by the very nature of its practice, however, is very difficult to define. As noted in the introduction, formal attempts at definition break down with changes in attitudes and patterns of practice. Many physicians who would not consider themselves CAM practitioners prescribe hippotherapy or supervise a conductive education session and, therefore, consider these methods to have entered standard practice. It is easy to answer that there is minimal to no evidence of efficacy of these methodologies in the literature. For example, a Medline review of 'aquatherapy' and

Table VI: Logistic regression for use of CAM

\begin{tabular}{lrrr}
\hline Factor & $p$ & Odds ratio & 95\% confidence interval \\
\hline Parental use of CAM & 0.02 & 2.1 & 1.1 to 3.8 \\
Lack of independent mobility & $<0.01$ & 2.5 & 1.3 to 4.7 \\
Younger age & $<0.01$ & 0.91 & 0.85 to 0.98
\end{tabular}

$\mathrm{R}^{2}=0.10$ 
'hydrotherapy' revealed only six articles about children with $\mathrm{CP}$ and this common (25\% of our population) clinical practice, none of which appeared to be clinical trials. Presence or absence of scientific proof of clinical efficacy, however, is not part of the definition for CAM and, therefore, it not a good reason to include or exclude a treatment from the list. A related problem is the lack of definition for each therapy. Massage therapy, for example, may be administered by a massage therapist, a physical therapist, a nurse, or any of a number of other individuals. Once again, the practice of alternative therapy does not lend itself well to precision. In defining our list, we therefore chose those forms of therapies that seemed to us and to most of our colleagues to be 'off the beaten path' of standard practice, and to some degree, attractive to families for just that reason. Our goal in designing this survey was to find out who were the families that had this attraction, and what were their motivating factors.

The high prevalence of CAM users noted in our survey is reflective of the high interest in new and different therapies that has always been present among families of children with CP. Even so-called 'standard care' for this population has always had somewhat of a non-standard feel, from Bobath (1967) techniques and neurodevelopmental therapy (known as NDT; Butler and Darrah 2001) to selective dorsal rhizotomy, which has some fairly good studies suggesting efficacy of the procedure (Steinbok et al. 1997, McLaughlin et al. 2002). However, many questions continue to be raised about electrophysiological techniques (Steinbok et al. 1994, Logigan et al. 1996). Electrical stimulation protocols, for example, came close to inclusion as CAM but were finally excluded from our list because they are generally presented 'within the medical model'. CP is a chronic syndrome which has a variety of treatments and interventions, but certainly has no 'cure'. A large number of CAM users have chronic syndromes (Spigelblatt et al. 1994, Ottolini et al. 2001) for which cures are elusive. Many CAM therapies involve increased contact time between the child and the family. The Euromed Adeli Suit program in Poland, for example, requires a family member to spend 4 weeks in close contact with their child, far away from the distractions of home and other family members. Increased parental involvement appeared to have beneficial effects in a group of children with CP who played games for several weeks and were then compared to a group who received NDT therapy (Palmer et al. 1988). A similar idea was suggested by the study group who noted that children who received a placebo demonstrated similar improvements in GMFM scores to children who had hyperbaric oxygen therapy (Collet et al. 2001). The beneficial effects perceived after CAM treatments (56\% of families in our study were pleased) combined with the lack of curative 'standard treatment', and then combined with support groups and internet networks most likely generate the $56 \%$ prevalence noted in this study.

The predictive factors relating to the child were a younger age compared to those who did not use CAM and more motor involvement (lack of independent ambulation was significant with regression, and quadriplegia and spasticity at least with univariate analysis). Both Spigelblatt et al. (1994) and Ottolini et al. (2001) noted older age children more commonly receiving CAM in their study. Spigelblatt and coworkers (1994) noted that their finding may relate to the fact that chronic diseases, which are the most common treatment targets in CAM, are not common in children less than 1 year old. Indeed, most of the chronic diseases mentioned, such as asthma, and headaches, are often first diagnosed in older children. CP, on the other hand, is generally diagnosed within the first or second year of life. Therefore, parents are attuned to their child's problems earlier in life, and may find reasons to choose CAM earlier. Many of the CAM methodologies designed for CP, such as aquatherapy, hippotherapy, and conductive education are aimed at motor problems. Generally, it is felt that they will be most helpful in the earlier developmental years, which may account for the higher prevalence in younger, more motor involved children.

Parental factors such as higher level of maternal education and previous use of CAM by the family were also noted by others (Spigelblatt et al. 1994, Ottolini et al. 2001). Spigelblatt et al. (1994) suggested that the more educated mothers would be exposed to more sources of information that could increase their interest in CAM. It is tempting to hypothesize that they may also turn more of their attention and energies to their children than the fathers do, which may account for the lack of correlation with paternal education. Fathers whose children were treated with CAM were slightly older, which was noted by Ottolini et al. (2001) as well. Although income was not identified as a predictor, it may be hypothesized that older parents may have more disposable income available for CAM treatment that is not covered by insurance.

Parental use of CAM was strongly associated with choosing CAM for their child. It is clear that families who have used CAM would have more information about and less prejudice against unconventional therapies. Satisfaction with their own treatment (which was found in 88\%) would logically lead to considering CAM for their child. These families would also be more familiar with routes of access and reimbursement, which theoretically could be hindrances to choosing CAM. However, it is particularly notable that satisfaction with the child's CAM therapy was significantly higher in the families who had used CAM for themselves than in those who did not. This finding is not as obvious as it would seem. First of all, most of the parents used a different form of CAM than they chose for their child (see Tables III and V). Second, even if both the parent and the child used the same form of CAM, the conditions being treated were completely different. We would never assume that a mother would see the benefits of baclofen for her child with CP because she had once had physical therapy for back pain, for example. It would appear, to some degree, that these findings imply that CAM therapies can be considered to have a strong commonality to them. It is beyond the scope of this work to engage in a full analysis of this idea, but one could speculate on such factors as the different nature of the therapies when compared to more conventional treatments. That doctors are perceived to dislike them, and the increased control they give the family since they can often be obtained without a prescription, as well as the 'natural' or holistic character of the therapies, or other factors are not yet understood. Whatever these characteristics are, they make CAM different from standard therapies, yet similar to each other, and hold out an appeal to some families who will use the therapies for themselves and their children, and find satisfaction with them.

\section{Conclusion}

CAM use is widespread for children with CP, with a prevalence rate of $56 \%$ noted for this clinic population. The prevalence may be somewhat higher, as families who only use CAM would 
not appear in our clinic. The children who used CAM were younger had more motor involvement than those who did not. The mothers who chose CAM were better educated, and the fathers were slightly older. Parental use of CAM was highly associated with choosing CAM for the child with $\mathrm{CP}$ and for eventual satisfaction with the treatment. This was noted despite the fact that the symptoms and the treatments of the parent and the child were completely different. Even though the above factors were significantly correlated with CAM use, the regression model only accounted for about $10 \%$ of the variability, indicating that there is still much that we do not know about why people choose CAM. It is important to note that this high rate of CAM use in no way implies that parents have given up on traditional 'standard' medical care. Less than $1 \%$ of respondents stated that they chose CAM because they did not trust traditional medicine. Caregivers of children with CP must increase their awareness and understanding of these treatment modalities, and become better counselors for their patients. Even though the families appear to be better educated, this does not necessarily mean that they have the biomedical information necessary to make a proper assessment of a treatment choice. Further contemplation and research is required to determine what factors make CAM modalities desirable and effective, and to consider how these factors can be woven into the 'standard care' that we give children with CP, and indeed all children.

\section{DOI: $10.1017 /$ S0012162203000707}

Accepted for publication 17th February 2003.

\section{Acknowledgements}

We gratefully acknowledge Katherine Chang MD, Robert A Werner $\mathrm{MD}$, and Margrethe Hackett for their assistance in preparing this manuscript.

\section{References}

American Academy of Pediatrics Committee on Children with Disabilities. (2001) Counseling families who choose complementary and alternative medicine for their child with chronic illness and disability. Pediatrics 10\%: 598-601.

Astin JA. (1998) Why patients use alternative medicine: results of a national survey. JAMA 2\%9: 1548-53

Balon J, Aker PD, Crowther ER, Danileson C, Cox PG, O'Shaughnessy D, Walker C, Goldsmith CH, Duku E, Sears MR. (1998) A comparison of active and simulated chiropractic manipulation as adunctive treatment for childhood asthma. NEnglJMed 339: 1013-20.

Baumgaertel A. (1999) Alternative and controversial treatments for attention deficit/hyperactivity disorder. Pediatr Clin NAm 46: 977-92.

Bobath B. (1967) The very early treatment of cerebral palsy. Dev Med Child Neurol 9: 373-90.

Butler C, Darrah J. (2001) Effects of neurodevelopmental treatment (NDT) for cerebral palsy: an AACPDM evidence report. Dev Med Child Neurol 43: 778-90.

Collet JP, Vanasse M, Marois P, Amar M, Goldberg J, Lambert J, Lassonde M, Hardy P, Fortin J, Tremblay SD, Montgomery D, Lacroix J, Robinson A, Majnemer A. (2001) Hyperbaric oxygen for children with cerebral palsy: a randomized multicentre trial Lancet 35\%: 582-6.

Eisenberg DM, Kessler RC, Foster C, Norlock FE, Calkins DR, Deblanco TL. (1993) Unconventional medicine in the United States: prevalence, costs and patterns of use. NEnglJMed 328: 246-52.

Eisenberg DM, Davis RB, Ettner SL, Appel S, Wilkey S, Van Rompay M, Kessler RC. (1998) Trends in alternative medicine in the United States, 1990-1997: results of a follow-up national survey. JAMA 280: 1569-75.

Friedman T, Slayton W, Allen L, Pollock BH, Dumont-Driscoll M, Mehta P, Graham-Pole J. (1997) Use of alternative therapies for children with cancer. Pediatrics 100: E1.
Ireland M, Olson M. (2000) Massage therapy and therapeutic touch in children: state of the science. Altern Ther Health Med 6: 54-63. Kemper KJ. (1996) The Holistic Pediatrician. New York: Harper Collins. Logigan EL, Shefner JM, Goumnerova L, Scott M, Soriano S, Madsen J. (1996) The critical importance of stimulus intensity in intraoperative monitoring for partial dorsal rhizotomy. Muscle Nerve 19: 415-22.

McLaughlin J, Bjornson K, Temkin N, Steinbok P, Wright V, Reiner A, Roberts T, Drake J, O'Donnell M, Rosenbaum P, Barber J, Ferrel A. (2002) Selective dorsal rhizotomy: meta-analysis of three randomized controlled trials. Dev Med Child Neurol 44: 17-25.

National Center for Complementary and Alternative Medicine. (2002) What is Complementary and Alternative Medicine? Publication No. D156. Bethesda, USA: National Center for Complementary and Alternative Medicine.

Nickel RE. (1996) Controversial therapies for young children with developmental disabilities. Infants Young Child 8: 29-40.

Ottolini MC, Hamburger EK, Loprieato JO, Coleman RH, Sachs HC, Madden R, Brasseux C. (2001) Complementary and alternative medicine use among children in the Washington DC area. Ambulat Pediatr 2: 122-5.

Palmer FB, Shapiro BK, Wachtel RC, Allen MC, Hiller JE, Harryman SE, Mosher BS, Meinert CL, Capute AJ. (1988) The effects of physical therapy on cerebral palsy: a controlled trial in infants with spastic diplegia. NEnglJ Med 318: 803-8.

Rusy LM, Weisman SJ. (2000) Complementary therapies for acute pediatric pain management. Pediatric Clinics of North America 4\%: 589-99.

Sheler JL. (2002) Faith in America. US News and World Reports. May 6, 132: 40-9.

Sikand A, Laken M. (1998) Pediatricians' experience with and attitudes toward complementary/alternative medicine. Arch Pediatr Adolesc Med 152: 1059-64.

Southwood TR, Nalleson PN, Roberts-Thompson PJ. (1990) Unconventional remedies used for patients with juvenile arthritis. Pediatrics 85: 150-4.

Spigelblatt L, Laine Ammara G, Pless IB, Guyver A. (1994) The use of alternative medicine by children. Pediatrics 96: 811-14.

Steinbok P, Keyes R, Langill L, Chochrane DD. (1994) The validity of electrophysiological criteria used in selective functional posterior rhizotomy for treatment of spastic cerebral palsy. JNeurosurg 81:354-61.

Steinbok P, Reiner AM, Beauchamp RD, Armstrong RW, Cochrane DD, Kestle J. (1997) A randomized clinical trial to compare selective posterior rhizotomy plus physiotherapy with physiotherapy alone in children with spastic diplegic cerebral palsy. Dev Med Child Neurol 39: 178-84.

Stern RC, Canada ER, Doershuk CF. (1992) Use of nonmedical treatment for cystic fibrosis patients. JAdolesc Health 13: 612-15.

\section{Appendix I: Complementary and alternative therapy definitions}

Ayurveda: Includes diet and herbal remedies and emphasizes use of body, mind, and spirit in disease prevention and treatment.

Euromed Adeli Suit: Provides resistance of some movements, and is purported to improve sensory feedback during movement.

Feldenkrais Method: Emphasizes body awareness through small, repeated movements and gentle touch, leading to awareness, flexibility, and coordination.

Homeopathy: Highly diluted quantities of medicinal substances are given to cure symptoms, when the same substances given at higher or more concentrated doses would actually cause those symptoms. Reiki: Based on the belief that when spiritual energy is channeled through a Reiki practitioner, the patient's spirit is healed, which in turn heals the physical body.

Rolfing (or Structural Integration): Joint mobilization and deep myofascial release techniques which are supposed to integrate structure and function. A 'Rolfer' helps clients to release inhibiting movement patterns and gives them techniques to change. 